06

\title{
Управление фрактальностью и размером серебряных кластеров при одностадийном синтезе гетероструктур $\mathrm{Ag}-\mathrm{ZnO}$
}

\author{
() Н.Д Якушова ${ }^{1}$, И.А Аверин ${ }^{1}$, И.А Пронин ${ }^{1,2, \text {, А.А Карманов }}{ }^{1}$, Е.А. Алимова ${ }^{1}$, В.А Мошников ${ }^{2}$, \\ Е.И Теруков ${ }^{3}$ \\ ${ }^{1}$ Пензенский государственный университет, Пенза, Россия \\ ${ }^{2}$ Санкт-Петербургский государственный электротехнический университет „ЛЭТИ“, Санкт-Петербург, Россия \\ ${ }^{3}$ Физико-технический институт им. А.Ф. Иофрфе РАН, Санкт-Петербург, Россия \\ ฯ E-mail: pronin_i90@mail.ru
}

Поступило в Редакцию 20 мая 2020 г.

В окончательной редакции 20 мая 2020 г.

Принято к публикации 28 мая 2020 г.

\begin{abstract}
В рамках золь-гель-метода разработаны приемы совместного и одновременного синтеза фрактальных нанои микрокластеров серебра и матрицы металлооксидного полупроводникового материала ZnO. Продемонстрирована возможность гибкого управления размером и фрактальной размерностью металлических структур путем изменения концентрации нитрата серебра в исходном золе. Предложенные подходы смогут найти применение при изготовлении фотокатализаторов, термисторов, биосенсоров, а также других приборов и устройств нано- и микросистемной техники.
\end{abstract}

Ключевые слова: оксид цинка, золь-гель-метод, фрактал, $\mathrm{Ag}-\mathrm{ZnO}$.

DOI: 10.21883/PJTF.2020.17.49890.18386

Разработка воспроизводимых подходов синтеза композитных материалов фрактальные нано-, микроструктуры серебра-полупроводниковый оксидный материал $\left(f r-\mathrm{Ag} / M e_{x} \mathrm{O}_{y}\right)$ представляет большой научный и практический интерес в таких областях, как фотокатализ, фотовольтаика, сенсорика, нано- и микросистемная техника. Например, традиционный подход к изготовлению плазмонных фотокатализаторов состоит в формировании на поверхности полупроводникового материала наночастиц благородных металлов с различными размером и формой [1]. При этом частицы выступают в роли „антенн“, сильно поглощающих и концентрирующих энергию за счет явления поверхностного плазмонного резонанса. Замена наночастиц благородных металлов на фрактальные микро- и наноструктуры, демонстрирующие широкий спектральный отклик от инфракрасной до ультрафиолетовой области [2], позволяет существенно повысить эффективность плазмонных фотокатализаторов.

Анализ литературы показывает, что использование серебряных дендритных нано- и микроструктур позволяет существенно улучшить параметры биосенсоров на основе поверхностно-усиленного комбинационного рассеяния [3], газовых сенсоров [4], солнечных элементов, сенсибилизированных красителем [5], а также открывает путь создания супергидрофобных поверхностей с уникальными каталитическими, самоочищающимися, антикоррозийными и противообледенительными свойствами [6].

Несмотря на важность научно-технических решений, которые могут быть реализованы при создании иерархических гетероструктур $f r-\mathrm{Ag} / M e_{x} \mathrm{O}_{y}$ с заданной фрак- тальностью и числом уровней иерархии, в настоящее время, как правило, серебряные агрегаты и полупроводниковая матрица синтезируются отдельно друг от друга с дальнейшим их объединением. Например, известна эффективная методика синтеза фрактальных структур серебра путем его восстановления из раствора нитрата аскорбиновой кислотой [7]. При этом изменение концентрации прекурсоров данным способом позволяет получать частицы серебра с разнообразными структурными особенностями: от сферических до иерархических с заданным числом уровней скейлинга. Но разработка методов синтеза структур $f r-\mathrm{Ag} / \mathrm{Me}_{x} \mathrm{O}_{y}$ в одном цикле остается нерешенной проблемой и представляет особый интерес.

В настоящей работе предложены приемы совместного и одновременного синтеза фрактальных нано- и микрокластеров серебра и матрицы полупроводникового оксида цинка для широкого спектра технических приложений.

Для получения нано- и микроструктур $f r-\mathrm{Ag} / \mathrm{ZnO}$ была использована модифицированная методика, описанная в [8], на первом этапе которой в золь дополнительно вводился нитрат серебра. Было приготовлено три серии образцов, содержащих 2, 3.5 и 5 at.\% серебра $(f r-\mathrm{Ag}(0.02) / \mathrm{ZnO}, f r-\mathrm{Ag}(0.035) / \mathrm{ZnO}, f r-\mathrm{Ag}(0.05) / \mathrm{ZnO})$ в исходном золе. Полученный золь наносился на кремниевые подложки методом центрифугирования с последующим отжигом в течение $1 \mathrm{~h}$ при температуре $550^{\circ} \mathrm{C}$. Анализ результатов, полученных с помощью сканирующей электронной микроскопии и энергодисперсионного анализа, позволяет сделать следующие выводы. 

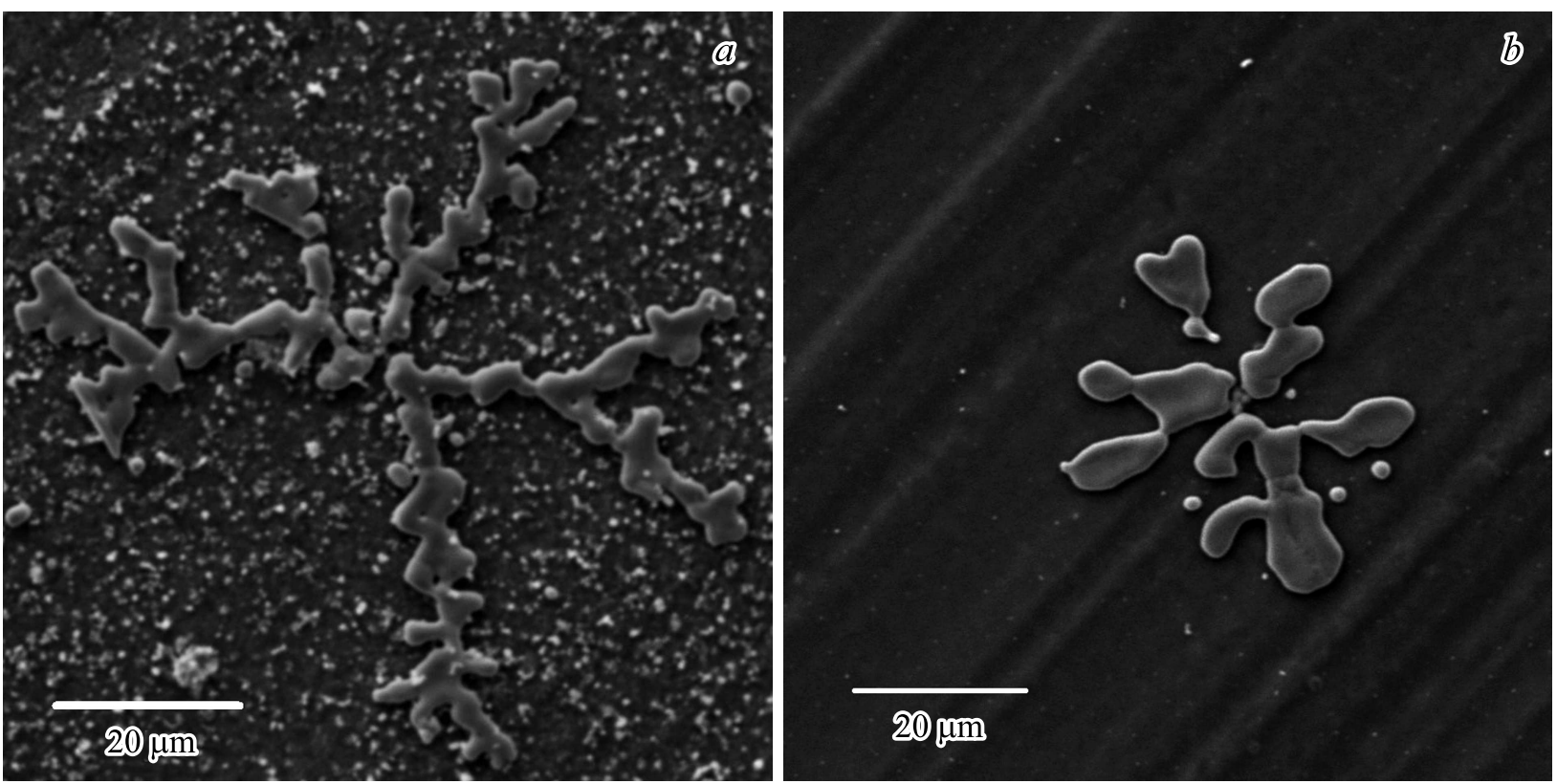

Микрофотографии $f r-\mathrm{Ag}(0.05) / \mathrm{ZnO}(a)$ и $f r-\mathrm{Ag}(0.02) / \mathrm{ZnO}(b)$.

1. Базовая пористая матрица состоит из оксида цинка, сформированного в результате золь-гель-перехода, и представляет собой иерархическую структуру из соединенных ветвей со средним диаметром ветвей $1-2 \mu \mathrm{m}$ на нижнем уровне скейлинга и 5-10 $\mu \mathrm{m}$ на верхнем уровне скейлинга. В свою очередь ветви $\mathrm{ZnO}$ собраны из квазисферических агрегатов со средним размером 50-100 nm. Данная структура является традиционной для представленной методики синтеза, механизм ее формирования более подробно изложен нами в работах $[9,10]$.

2. Фрактальные агрегаты серебра консолидируются с базовой матрицей на последующих этапах образования ксерогеля. Протекающие физико-химические процессы по природе близки к процессам создания наноструктур тройного соединения $\mathrm{ZnFe}_{2} \mathrm{O}_{4}$ из наночастиц $\mathrm{ZnO}$ и $\mathrm{Fe}_{2} \mathrm{O}_{3}$ методом химического соосаждения [11], однако в отличие от технологии получения тройных соединений в нашем случае не нужно регулировать скорости соосаждения, так как образуется гетерогенный интерфейс $f r-\mathrm{Ag} / \mathrm{ZnO}$.

По форме кластеры $f r$-Ag на поверхности пленок близки к фрактальным агрегатам Виттена-Сэндера [12] (на рисунке для примера показаны микрофотографии поверхностных агрегатов $f r-\mathrm{Ag}$, полученных из золей с содержанием $\mathrm{Ag}^{+} 5(a)$ и 2 at.\% $\left.(b)\right)$, однако механизм роста отличается от диффузионно-лимитированной агрегации, поэтому представляет интерес оценка фрактальной размерности Хаусдорфа-Безиковича. В нашем случае фрактальная размерность кластеров $D_{F}$ была рассчитана по методу Мандельброта-Пассойя-Полле [13]. В этом методе, который также называется методом „область-периметр“, для оценки фрактальной размер- ности шероховатой поверхности $D_{F}$ используют свойства самоаффинности сечений-срезов на разных высотах, параллельных основанию, и корреляционную связь между значениями периметров и значениями площадей фрактальных областей. Полученные экспериментальные данные свидетельствуют о том, что фрактальная размерность зависит от атомной доли серебра и может в диапазоне концентраций $2 \leq\left[\mathrm{Ag}^{+}\right] \leq 5$ at.\% аппроксимироваться линейной зависимостью

$$
D_{F}=(0.10 \omega+2.15) \pm 0.02 \text {, }
$$

где $\omega$ - доля серебра [at.\%]. Следует, однако, отметить, что линейная зависимость в достаточно узком концентрационном диапазоне не отражает общий характер влияния на фрактальную размерность (так как фрактальная размерность зависит не только от концентрации серебра, но и от других факторов, влияние которых еще не изучено). Следует также отметить, что увеличение концентрации серебра в исходном золе сопровождается ростом агрегатов: для серии $f r-\mathrm{Ag}(0.02) / \mathrm{ZnO}$ средний размер составляет $35 \mu \mathrm{m}$, а для серии $f r-\mathrm{Ag}(0.05) / \mathrm{ZnO}-$ $65 \mu \mathrm{m}$.

По внешнему виду сформированных серебряных островков, а также исходя из физико-химических условий их получения были предложены основные модельные представления образования и развития данных фрактальных объектов. Прежде всего размеры базовых элементов позволяют предположить, что они образуются на предварительном этапе до моментов самосборки. Этот процесс может протекать в каплях растворителя, содержащего ионы серебра. Сами капли являются продуктом параллельно протекающих процессов гидролиза и поликонденсации, характерных для золь-гель-технологии. 
Из внешнего вида следует, что данные капли довольно подвижны на поверхности матрицы и собираются вдоль закрепленных неподвижно центров. Ранее в работе [14] исследовались природа образования таких неподвижных центров на пористом кремнии и модельные представления о том, что заполненная пора с мениском растворителя, выходящего на поверхность, удовлетворительно согласуется с концепцией, согласно которой сборка кластеров осуществляется вокруг центра, закрепленного на выходе пор. В пользу представлений о подвижных каплях, которые сливаются при сближении друг с другом, свидетельствует то, что между этими элементами иногда наблюдаются прослойки. В свете изложенного выше мы предлагаем модель, в которой рост первичных элементов, возникающих в каждой из капель, соответствует на начальных этапах росту по механизму, близкому к виттен-сэндеровскому, т.е. в результате диффузионнолимитированной агрегации. В этом случае размеры и форма таких первичных элементов будут зависеть от концентрации серебра и времени сборки: от концентрации зависит конечный размер, а от времени - локальная фрактальная размерность. Тем не менее при длительной выдержке может происходить переход от массового фрактала к поверхностному или полное исчезновение фрактальности в наночастице (однако при слиянии таких частиц фрактальность может проявляться в виде шероховатости вдоль покрытия). Важным моментом является технологическая гибкость управления данными процессами образования первичных элементов за счет вариации концентрации ионов серебра, температуры, а также за счет добавления дополнительных веществ, изменяющих вязкость и поверхностное натяжение образующихся капель.

Таким образом, в работе впервые продемонстрирована возможность одностадийного синтеза гетероструктур фрактальные кластеры серебра-оксид цинка. При этом показано, что особенности иерархического нанодизайна материалов определяются содержанием катионов серебра в исходном золе. Предложенные приемы могут быть полезны при изготовлении широкодиапазонных фотокатализаторов нового поколения, а также различных устройств нано-, микроэлектроники и микросистемной техники.

\section{Финансирование работы}

Работа выполнена при финансовой поддержке Российского фонда фундаментальных исследований в рамках научного проекта № 19-08-00924, а также стипендии Президента РФ (СП-84.2018.1).

\section{Конфликт интересов}

Авторы заявляют, что у них нет конфликта интересов.

\section{Список литературы}

[1] Jiang Z., Jiang D., Wei W., Yan Z., Xie J. // J. Mater. Chem. A. 2015. V. 3. N 46. P. 23607-23620.

[2] Takeyasu N., Taguchi N., Nishimura N., Cheng B.H., Kawata S. // APL Photon. 2016. V. 1. N 5. P. 050801.

[3] Wen J., Song F., Du Y., Yu W., Qiang R. // Mater. Sci. Eng. 2019. V. 688. N 3. P. 033040.

[4] Navaneethan M., Patil V.L., Ponnusamy S., Muthamizhchelvan C., Kawasaki S., Patil P.S., Hayakawa Y. // Sensors Actuators B. 2018. V. 255. P. 672-683.

[5] Amiri O., Salavati-Niasari M., Mir N., Beshkar F., Saadat M., Ansari F. // Renewable Energy. 2018. V. 125. P. 590-598.

[6] Cui S., Lu S., Xu W., Wu B., Zhao N., He G., Houa X., Zhang H. // New J. Chem. 2016. V. 40. N 10. P. 8897-8904.

[7] Sigaev A.P., Averin I.A., Pronin I.A., Karmanov A.A., Yakushova N.D., Moshnikov V.A. // J. Phys.: Conf. Ser. 2019. V. 1410. N 1. P. 012034.

[8] Пронин И.А., Аверин И.А., Якушова Н.Д., Карманов А.А., Мочников В.А., Теруков Е.И. // Письма в ЖТФ. 2019. Т. 45. B. 12. C. $45-48$.

[9] Dimitrov D.T., Nikolaev N.K., Papazova K.I., Krasteva L.K., Bojinova A.S., Peshkova T.V., Kaneva N.V., Pronin I.A., Averin I.A., Yakushova N.D., Karmanov A.A., Georgieva A.T., Moshnikov V.A. // Appl. Surf. Sci. 2017. V. 392. P. 95-108.

[10] Pronin I.A., Averin I.A., Yakushova N.D., Dimitrov D.T., Krasteva L.K., Papazova K.I., Chanachev A.S., Bojinova A.S., Georgieva A.T., Moshnikov V.A. // Sensors Actuators A. 2014. V. 206. P. 88-96.

[11] Карпова С.С., Мошников В.А., Мякин С.В., Коловангина Е.C. // ФТП. 2013. Т. 47. В. 3. С. 369-372.

[12] Максимов А.И., Мошников В.А., Таиров Ю.М., Шилова O.A. Основы золь-гель-технологии нанокомпозитов. 2-е изд. СПб.: Техномедиа, 2008. 255 с.

[13] Mandelbrot B.B., Passoja D.E., Paullay A.J. // Nature. 1984. V. 308. N 5961. P. 721-722.

[14] Власюк Д.П., Мамыкин А.И., Мошников В.А., Муратова Е.Н. // Физика и химия стекла. 2015. Т. 41. № 5. С. 745 752. 